\title{
CONTRASTIVE CAUSATION IN THE LAW
}

\author{
Jonathan Schaffer* \\ Australian National University
}

What conception of causation is at work in the law? I argue that the law implicitly relies on a contrastive conception. In a liability case where the defendant's breach of duty must be shown to have caused the plaintiff's damages, it is not enough to consider what would have happened if the cause had not occurred - the law instructs us to look to a specific replacement for the cause, which in this case is the hypothetical scenario in which the defendant acted lawfully. And it is not enough to ask if the effect would still have occurred - the law requires us to look to a specific replacement for the effect, which in this case is the hypothetical outcome in which the plaintiff came off better. In place of "but for the defendant's breach, the plaintiff's damage would not have occurred," I suggest the more explicit "if the defendant had acted lawfully, the plaintiff would have met a better fate." An explicitly contrastive approach can thus potentially help the lawyer phrase her causal question in a more explicit way, while shedding light on our conception of causation.

According to David Hume, our concepts of causation, resemblance, and contiguity are the foundation of all of our reasoning concerning matters of fact and are "to us the cement of the universe."1 Our concept of causation seems crucial to legal thought. Many liability doctrines in both criminal law and torts explicitly require that the defendant has caused harm to the plaintiff. $^{2}$ Assuming that the law uses our concept of causation and not its own stipulatively defined notion, our concepts of causation and of legal liability may prove mutually illuminating.

And so authors from H.L.A. Hart and Tony Honoré ${ }^{3}$ to Moore ${ }^{4}$ have taken up the unifying project of spelling out how causal thinking works in

*Thanks especially to Jane Stapleton for her knowledge and patience, and to Alex Broadbent for insightful discussion. I am also indebted to helpful comments from Michael Moore, Amit Pundik, Carolina Sartorio, Guy Sela, The Oxford Jurisprudence Discussion Group, and the participants at the Putting Causation in Context: Cause and Effect in Law and Philosophy conference at Cambridge in 2009.

1. David Hume, Abstract of A Treatise of Human Nature, in An ENQuiry Concerning Human Understanding, 133-145 (Peter Millican ed., Oxford University Press 2007) (1740), at 145.

2. Michael Moore, Causation and Responsibility (2009), at 3.

3. H.L.A. Hart \& Tony Honoré, Causation in the LaW (2d ed. 1985).

4. MOORE, supra note 2. 
the law. What follows is a continuation of this project, bringing to bear a contrastive conception of causation on which assessing whether $c$ causes $e$ involves contrasting $c$ with some relevant alternative $c^{*}$ and contrasting $e$ with some relevant alternative $e^{*}$. I argue that this contrastive conception of causation makes the best sense of legal liability and causal judgments made in the courtroom.

Causal judgments made in the courtroom are often explicitly based on the sine qua non test. For instance, in a tort of negligence it will typically be asked: Would the actual damage to the plaintiff still have occurred had the defendant's actual breach of duty not occurred? I am arguing that the more useful test, which is implicitly at work behind the sine qua non test and so in fact is implicitly in use, is the following test: Would a better outcome for the plaintiff have occurred than the actual outcome had the defendant acted lawfully instead of breaching duty? Instead of "but for the defendant's breach, the plaintiff's damage would not have occurred," I suggest the more explicit "if the defendant had acted lawfully, the plaintiff would have met a better fate."

This proves to be a more discriminating test in the following two ways. First, instead of looking at scenarios in which the defendant's actual breach of duty did not occur (which might involve scenarios in which the defendant acts unlawfully in some other way), one is specifically instructed to consider the alternative supposition of lawful conduct for the defendant. Second, instead of then looking to see whether the actual harm to the plaintiff would still have occurred (when it might merely have been replaced by some equal or worse harm instead), one is specifically guided to look for the alternative of a comparatively better outcome for the plaintiff. An explicitly contrastive approach can thus potentially help the lawyer phrase her causal question in a more explicit way.

\section{OVERVIEW}

In Section 1, I describe and motivate the contrastive view of causation. This includes a discussion of causation by absences and a connection to causal modeling techniques. In Section 2, I turn to causation in the law. I argue that specification of the causal contrast as lawful conduct is needed so that the right alternative gets assessed, and I argue that specification of the effectual contrast as the better outcome is needed so that the right damages get assigned. The contrastive view is not intended as a revisionary proposal but rather as a description of what is implicit in our practice, and so I argue that the sine qua non test (and also the necessary element of a sufficient set [NESS] test) is implicitly contrastive. I conclude in Section 3 by situating the resulting conception of causation in comparison to the recent views of Jane Stapleton, Moore, and Alex Broadbent. ${ }^{5}$ The contrastive view preserves and

5. Jane Stapleton, Choosing What We Mean by "Causation" in the Law, 73 Mo. L. Rev. 433-480 (2008); Moore, supra note 2; Alex Broadbent, Fact and Law in the Causal Inquiry, 15 Legal Theory 173-191 (2009). 
explains Stapleton's insight that causal judgments in the law are sensitive to the underlying inquiry, reconciling this with Moore's insight that causal judgments in the law are focused on the metaphysical relation of causation, while improving on the particulars of Broadbent's contrastive approach.

\section{CONTRASTIVE CAUSATION}

\section{A. The Contrastive View}

It is widely assumed-though never argued for-that causation is a relation with two relata: the cause and the effect. Most theorists start by writing the schema " $c$ causes $e$ if and only if ...", and then consider how to continue. The contrastive view challenges this starting point. On the contrastive view, causation involves additional relata. On the version of the contrastive view I am defending, there is also the causal contrast and the effectual contrast. Instead of just " $c$ causes $e$," we have " $c$ rather than $c^{*}$ causes $e$ rather than $e^{*} . "$ "

The contrastive thesis is thus a thesis about the number and the roles of the causal relata. In particular it is the thesis that there are four causal relata in the roles of cause, causal contrast, effect, and effectual contrast, as follows:

(Contrast) The causal relation has the form: $c$ rather than $c^{*}$ causes $e$ rather than $e^{*}$

Causal judgment is judgment about the causal relation and so-given Contrast-makes reference not merely to cause and effect (as is usually thought) but also to their respective contrasts.

Contrast is neutral on the category of the causal relata and on the nature of the causal relation. As to the category of the causal relata, I assume that $c$ and $e$ are actual distinct events, where events are coarse-grained, world-bound individuals. I take $c^{*}$ and $e^{*}$ to be nonactual events that are noncompossible

6. The contrastive conception of causation builds on the following work: BAS VAN FrAASSEN, The Scientific Image (1980); Peter Lipton, Contrastive Explanation, in ExPlanation and ITs LimITS, 246-266 (Dudley Knowles ed., 1990); Christopher Read Hitchcock, A Generalized Probabilistic Theory of Causal Relevance, 97 SynTHESE 335-364 (1993); Christopher Read Hitchcock, The Role of Contrast in Causal and Explanatory Claims, 107 SynTHESE 395-419 (1996); JAMES WOODWARD, Making Things Happen: A Theory of Causal Explanation (2003); Cei Maslen, Causes, Contrasts, and the Nontransitivity of Causation, in CAUSATION AND COUNTERFACTUALS (John Collins, Ned Hall, \& L.A. Paul eds., 2004); Jonathan Schaffer, Contrastive Causation, 114 PHIL. Rev. 327-358 (2005); Jonathan Schaffer, Causal Contextualisms: Contrast, Default, and Model, in CoNTRASTIVISM IN PHILOSOPHY (Martijn Blaauw ed., forthcoming); and Robert Northcott, Causation and Contrast Classes, 139 PHIL. STud. 111-123 (2008), inter alia. For WoOdward, supra at 146, contrastivity is the natural consequence of a manipulationist view of causation:

Any manipulation of a cause will involve a change from one state to some specific alternative, and how, if at all, a putative effect is changed under this manipulation will depend on the alternative state to which the cause is changed. Thus, if causal claims are to convey information about what will happen under hypothetical manipulations, they must convey the information that one or more specific changes in the cause will change the effect (or the probability of the effect). This in turn means that all causal claims must be interpretable as having a contrastive structure. 
alternatives to $c$ and to $e$ (respectively). ${ }^{7}$ If we are concerned-as the law usually is where liability is concerned-with the behavior of a given defendant who has performed action $c$, then $c^{*}$ is the alternative action imagined for this defendant. And if we are also concerned with the damages incurred by a given plaintiff in outcome $e$, then $e^{*}$ is the alternative outcome imagined for this plaintiff.

As to the causal relation itself, I offer no analysis. Just as there is no successful analysis of the form " $c$ causes $e$," so I do not expect any successful analysis of the contrastive form " $c$ rather than $c^{*}$ causes $e$ rather than $e^{*} . " 8$ But just as there is a decent heuristic for " $c$ causes $e$ " in terms of the sine qua non test, so I can offer a related counterfactual heuristic in the contrastive case: $c$ rather than $c^{*}$ causes $e$ rather than $e^{*}$ (typically) if and only if the occurrence of $c^{*}$ counterfactually entails the occurrence of $e^{*}$. Instead of seeing whether the nonoccurrence of $c$ counterfactually entails the nonoccurrence of $e$, we look to whether the occurrence of the specified alternative $c^{*}$ counterfactually entails the occurrence of the specified alternative $e^{*}$, as per:

(Test) $c$ rather than $c^{*}$ causes $e$ rather than $e^{*}$ if and only if (typically) if $c^{*}$ would have occurred, then $e^{*}$ would have occurred ${ }^{9}$

Test will go wrong in cases of redundant causation (overdetermination and preemption). But since we can independently tell whether a case is one of redundant causation, and since Test goes right in most other (deterministic) cases, it provides a useful rule of thumb for working with Contrast.

Test will also go wrong in indeterministic cases. It can be extended to the indeterministic case in the usual way, namely by looking at the relative matter of counterfactual chance-raising. ${ }^{10}$ But it is not obvious that this way of extending to the indeterministic case fits the law. For instance, in Hotson $v$. East Berkshire Area Health Authority, ${ }^{11}$ sustained in Gregg v. Scott, ${ }^{12}$ the ruling on causation seems to turn on the notion of "the balance of probabilities," with the absolute requirement that the alternative scenario of lawful conduct

7. See Schaffer, Contrastive Causation, supra note 6; and Jonathan Schaffer, The Metaphysics of Causation, STANFORD ENCyClopedia OF PHILOsOPHY (2007), available at http://plato.stanford.edu/entries/causation-metaphysics, for more detailed discussion of these issues.

8. I am in sympathy with Richard Fumerton \& Ken Kress, Causation and the Law: Preemption, Lawful Sufficiency, and Causal Sufficiency, 64 LAW \& ConTEMP. Probs. 83-105 (2001), at 105, when they warn: "[I]f the law is waiting for philosophers to offer something better than a prephilosophical grasp of what is involved in one thing causing another, the law had better be very patient indeed."

9. This heuristic can be rendered more precise by specifying the following restrictions on $c, e, c^{*}$, and $e^{*}$ : (i) $c$ and $e$ are actual distinct events; (ii) $c^{*}$ is a noncompossible alternative to $c$; and (iii) $e^{*}$ is a noncompossible alternative to $e$. I am considering only cases in which these restrictions are met. Note that $c$ and $e$ play an indirect role in Test via restrictions (ii) and (iii).

10. Cf. David Lewis, Causation, in 2 Philosophical Papers, 159-213 (1986); D.H. Mellor, The FACTS OF CAUSATION (1995).

11. Hotson v. E. Berkshire Area Health Auth., [1987] 2 All E.R. 909.

12. Gregg v. Scott, [2005] UKHL 2. 
involve at least a 50 percent chance of averting the harm. To avoid these complications, I restrict my present attention to the deterministic case.

\section{B. Absence Causation}

Why accept Contrast? That is, why think that causal judgment involves consideration of not just the cause and effect but also the causal contrast and effectual contrast? Arguably, causal and explanatory judgments in the sciences are always contrastive judgments. ${ }^{13}$ Elsewhere I offer a range of arguments for Contrast, maintaining that it provides a better understanding of absence causation, the fragility of events, the extensionality and transitivity of causal relations, our selection of "the cause" from among the many contributing factors, and the context sensitivity of causal discourse. ${ }^{14}$ Here I shall just discuss the issue of absence causation and (in Sec. I.C) add a further argument that Contrast provides a better fit with causal modeling.

I am revisiting absence causation for three reasons. First, doing so will enable me to display the contrastive view in action while supplying some initial motivation. Second, the issue of absence causation has direct relevance to negligence and other issues in the law. And third, in a recent and extraordinarily detailed discussion of causation in the law, Moore maintains that absence causation is metaphysically impossible;. He is thus driven to heroic lengths to make sense of legal liability. ${ }^{15}$ So revisiting absence causation sets the stage for a later comparison between the contrastive view and Moore's view (Sec. III.A).

Absence causation can appear paradoxical. On the one hand, there are at least four good reasons to allow absences to play some role in causal relations. First, some claims of absence causation are intuitively acceptable. For instance, if the gardener was supposed to water my flowers but instead spent the day drinking in the pub, then it seems right to judge that the gardener's not watering my flowers caused them to die.

13. See, e.g., W.M. Goodwin, Structural Formulas and Explanation in Organic Chemistry, 10 Found. CHEM. 117-127 (2008), on contrastive explanations in organic chemistry. Indeed, CARL CRAVEr, ExPlaINING THE Mind (2007), at 82-drawing on Schaffer, Contrastive Causation, supra note 6 -explicitly adopts Contrast in order to detail how causation works in neuroscience:

[T] he causal relata are contrasts. For the cause variable, the contrast is between the value of the variable as fixed by the ideal intervention and the value that the variable has in the control condition (that is, without intervention). For the effect variable, the contrast is between the value of the variable in the control condition (when one does not intervene on the cause variable), and its value in the experimental condition (when one does intervene on the cause variable). Causal statements are thus most clearly articulated when the describe a relationship between contrasts: $\mathrm{C}$ rather than not-C causes E rather than not-E. Different choices of contrast classes yield different causal claims.

14. Schaffer, Contrastive Causation, supra note 6; and Schaffer, Causal Contextualisms, supra note 6 .

15. MOORE, supra note 2. 
Second, absences play the predictive and explanatory roles of causes and effects. For instance, the pilot's not lowering the landing gear may be invoked to predict a crash or to explain why a crash occurred. These are the predictive and explanatory signatures of causation, and point toward the role that absences play in causation as it arises in scientific reasoning. ${ }^{16}$

Third, absence causation plays a crucial role in the law, as Hart and Honoré note:

There are frequent [legal] contexts when the failure to initiate or interrupt some physical process; the failure to provide reasons or draw attention to reasons which might influence the conduct of others; and the failure to provide others with opportunities for doing certain things or actively depriving them of such opportunities are thought of in causal terms. ${ }^{17}$

In this sense the law-using our ordinary concept of causation-is simply picking up on the intuitive acceptability of absence causation. The gardener may be legally liable for the death of my flowers.

Fourth and finally, absences mediate causation by disconnection, which features in some of the most paradigmatic causal scenarios. For instance, decapitation is a paradigmatic cause of death. But the causal process from decapitation to death is mediated by disconnection of an existing causal process. Decapitation causes death by preventing oxygenated blood from preventing brain starvation. The absence of blood flow to the brain mediates the dying. ${ }^{18}$

Yet on the other hand, there are at least two good reasons to be wary of allowing absence causation. First, some claims of absence causation are intuitively unacceptable. For instance, it seems wrong to judge that the queen of England's not watering my flowers caused them to die. Yet the gardener and the queen seem metaphysically on par, at least as measured by counterfactuals (both failures are sine qua non conditions) and as measured by physical connections such as energy flow (neither failure involves any energy flow to my flowers).

Second, absence causation seems metaphysically abhorrent. There is no energy-momentum flow or other physical process connecting cause and effect when absences are involved. Absences impart no oomph. As David Armstrong puts the point, "omissions and so forth are not part of the real

16. For more on the role of absence causation in scientific discourse, see Jonathan Schaffer, Causes Need Not Be Physically Connected to Their Effects: The Case for Negative Causation, in ConTEMPORARy Debates In Philosophy of SCIEnCE, 197-216 (Christopher Read Hitchcock ed., 2004), at 202-203.

17. HaRT \& HonORÉ, supra note 3, at 2-3.

18. Other paradigm cases of causation featuring disconnection include gun firings, heart failures, and muscle contractions (thus all human action). See Jonathan Schaffer, Causation by Disconnection, 67 PHIL. SCI. 285-300 (2000), for further discussion. 
driving force in nature. Every causal situation develops as it does as a result of the presence of positive factors alone." ${ }^{19}$ Similarly, Moore maintains:

$[\mathrm{O}]$ missions cause nothing. "Nothing comes from nothing, and nothing ever can" is good metaphysics, as well as catchy lyrics in musical productions. Absent elephants grow no grass by their absence; absent savings cause nothing, and certainly not the deaths they fail to prevent. ${ }^{20}$

Indeed, if omissions are just nothings, then they are not events and are thereby ineligible to participate in the causal relations between events.

Contrast allows for a resolution of the paradox of absence causation in two main parts. First, omission claims (such as "the gardener's failing to water my flowers") are treated as denoting actual events by negative description. ${ }^{21}$ Second, the use of the negative description is interpreted as setting the contextually implicit contrast to what was said to be absent. So, given that the gardener went to the pub instead of watering my flowers, the claim "the gardener's failing to water my flowers caused ... " will get interpreted with $c=$ the gardener's drinking at the pub (what actually transpired at the salient time), and $c^{*}=$ the gardener's watering my flowers (the nonactual contrast). In this sense, omission claims serve to contrast what actually happened with a relevant alternative, which implements Hart and Honoré's conception of omission claims: "The corrective here is to realize that negative statements like 'he did not pull the signal' are ways of describing the world, just as affirmative statements are, but they describe it by contrast." 22

The resolution allows for claims of absence causation to come out true; thus their intuitive plausibility and their role in science and the law. For instance, "the gardener's failing to water my flowers caused them to die" will come out (as above) with $c=$ the gardener's drinking at the pub, and $c^{*}=$ the gardener's watering my flowers. The most natural interpretation of the effect and its contrast is $e=$ the death of my flowers, and $e^{*}=$ my flowers surviving. Given that the counterfactual "if the gardener had watered my flowers, then they would have survived" is true, Test delivers

19. David Armstrong, The Open Door: Counterfactual versus Singularist Theories of Causation, in Causation And Laws of NATURE 175-185 (Howard Sankey ed., 1999), at 177.

20. MOORE, supra note 2 , at 54-55.

21. More precisely, I take the positive nominal "the gardener's watering my flowers" to have the following neo-Davidsonian form: $(\exists e)$ (Agent $(e)=$ the gardener \& Watering $(e) \&$ Patient $(e)=$ my flowers). There are various places where a negation can then be inserted. But in the context of causal discourse, I take the most natural reading to be: $(\exists e)(\operatorname{Agent}(e)=$ the gardener \& NOT (Watering $(e) \&$ Patient $(e)=$ my flowers)). Moreover, the existential quantifier will be contextually restricted to the salient time. So understood, "the gardener's not watering my flowers" denotes an event at the salient time in which the gardener did something that was not a watering of my flowers.

22. HART \& HONORÉ, supra note 3, at 38. This treatment can equally be seen as an implementation of Stapleton's idea that we need to compare the actual world (in which the gardener drank at the pub) with "a hypothetical world in which the gardener did provide the relevant contracted-for amount of artificial watering." Stapleton, supra note 5, at 436. Specification of the causal contrast is needed to implement this comparison (Sec. III.B). 
the correct verdict that $c$ rather than $c^{*}$ causes $e$ rather than $e^{*}$. (And if the counterfactual is false, then Test delivers the correct verdict as well, since in that sort of case the gardener has a successful defense.)

But what of the metaphysical and intuitive difficulties with absence causation? Metaphysically speaking, what the resolution does is to fit absence causation into the contrastive format for event causation. Omissions are not nothings but just ways to describe actual events that specify the relevant contrasts. Indeed, the resolution acknowledges Armstrong's point that positive factors are "the real driving force in nature." ${ }^{23}$ Contrast merely points out that differences in positive factors can drive nature in different ways. For instance, the difference between the gardener drinking at the pub and watering my flowers drives nature in a way that makes a difference to the survival of my flowers. Though no energy flow connects the gardener's drinking at the pub to the death of my flowers, what is salient in this case is that in the causal contrast scenario in which the gardener waters my flowers, there would have been a sustaining flow of energy to my flowers.

The one aspect of the paradox of absences that is not directly resolved is the problem of counterintuitive causal claims. Supposing that the queen actually sat on her throne at the relevant time, then Test rules that the queen's sitting on her throne rather than watering my flowers caused my flowers to die rather than survive. (Metaphysically, the gardener and the queen are completely on par vis-à-vis the fate of my flowers. This should not be denied.) So why do we blame the gardener and not the queen? I say, there is no metaphysical difference in causation but there is a normative difference in duties. The gardener had an obligation to water my flowers, while the queen did not. When I discuss contrastive causation in the law (Sec. II below), I propose that the schema we employ for responsibility has $c$ as the breach of duty and $c^{*}$ as lawful conduct. The queen cannot satisfy this schema for responsibility since she had no duty to water my flowers.

This schema for responsibility, I would suggest, is the one we naturally tend to employ where the causal attribution is serving a legal purpose. ${ }^{24}$ We want to hold the gardener liable, and we see both that he breached his duty to water my flowers, and that this breach-as contrasted with lawful conduct—made the difference as to the fate of my flowers. But when we ask if the queen is likewise liable, we find no analogous cause and causal contrast pair, where the cause is a breach of duty, the contrast is lawful conduct, and

23. Armstrong, supra note 19, at 177.

24. As Wright-drawing on the American Law Institute's Restatement of THE LAW OF TORTS-notes:

[I]n ordinary use the terms "cause" and "responsibility" have ambiguous and overlapping meanings, sometimes referring merely to the empirical fact of having contributed to a certain result, but at other times referring only to those contributing factors which are deemed to be most significant given the context and purpose of the particular inquiry.

Richard Wright, Once More into the Bramble Bush: Duty, Causal Contribution, and the Extent of Legal Responsibility, 54 VAND. L. REv. 1071-1132 (2001), at 1071. 
the fate of my flowers hangs in the balance. So we do not hold the queen liable for the fate of my flowers. Thus the contrastive account explains why we come to different causal judgments about the gardener and the queen in this case. We employ a particular contrastive schema that factors in their respective duties. ${ }^{25}$

\section{Causal Modeling}

Causal modeling techniques have led to breakthroughs in causal epistemology. While it was once accepted wisdom that one cannot infer causation from correlation, causal modeling techniques (as developed by Peter Spirtes, Clark Glymour, and Richard Scheines and Judea Pearl, inter alia) ${ }^{26}$ have refuted the accepted wisdom and provided precise and fruitful algorithms for causal discovery. A viable account of causal judgment must fit with the epistemology of causal modeling. I now provide further motivation for Contrast by arguing that it helps provide a fit. (This argument involves some minor technicalities not arising elsewhere in the paper. The reader unfamiliar with causal modeling and who already accepts the claim that Contrast is motivated may opt to skip this section.)

Causal models - in Pearl's framework ${ }^{27}$-involve specification of triples $<\boldsymbol{U}, \boldsymbol{V}, \boldsymbol{E}>$, where $\boldsymbol{U}$ is a set of exogenous variables, $\boldsymbol{V}$ is a set of endogenous variables, and $\boldsymbol{E}$ is a set of structural equations (with the constraint that $\boldsymbol{E}$ be such that all assignments of values to the members of $\boldsymbol{U}$ entail assignments of values to all the members of $\boldsymbol{V}$ ). Intuitively, one may think of $\boldsymbol{U}$ as representing the "initial conditions," $V$ as representing the "subsequent conditions," and $\boldsymbol{E}$ as representing the "counterfactual entailments" amongst the various conditions.

A variable $(U \in \boldsymbol{U}$ or $V \in V$ ) is allotted a fixed set of possible values representing a range of possible outcomes. For instance, if we are modeling a rock being thrown at a window, we might use a causal model with an endogenous variable Window $1 \in V$ representing the state of the window, with the following two possible values:

\section{Window1 = 1 if and only if ("iff") the window shatters 0 iff the window remains entirely intact}

25. Sarah McGrath, Causation by Omission: A Dilemma, 123 PHIL. STUd. 125-148 (2005), argues convincingly that our causal judgments have a normative element. This is why we call the gardener's failing to water the plants a cause of their death but do not call the queen's failing to water the plants a cause. Yet it seems deeply implausible to think that the causal relation itself should turn on normative considerations ( $c$ f. Richard Wright, Causation in Tort Law, 73 CAL. L. REV. 1737-1828 (1985), at 1798-1801). On the view I am suggesting, normativity enters only in the values we tend to be interested in for $c^{*}$ and $e^{*}$. But for any given setting of these values, contrastive causation is a completely objective matter. Thus Contrast can reconcile the normative elements of causal judgment with an objective metaphysical image.

26. Peter Spirtes, Clark Glymour, \& Richard Scheines, Causation Prediction and Search (1993); Judea Pearl, Causality: Models, Reasoning, and Inference (2000).

27. PEARL, supra note 27. 
But there are many other options. For instance, one might also employ Window $2 \in \boldsymbol{V}$ with different possible values, as follows:

Window $2=1$ iff the window shatters as it actually does 0 iff the window does not shatter as it actually does

Assuming that the window in fact shatters, the choice between Window1 and Window2 is a choice between two different contrasts with the actual window shattering. Deploying Window1 is tantamount to contrasting the window's shattering with an alternative in which it remains entirely intact, while deploying Window2 is tantamount to contrasting the window's shattering with an alternative in which it does not shatter as it actually does, which includes the prospect of it shattering in some other way. The choice between Window1 and Window2 can be understood as a choice between different ways of carving up the space of possibilities. Window1 lumps the possibility of the window shattering in some other way as the same sort of outcome as the actual outcome, while Window2 divides these outcomes as different.

It may turn out-depending on the rest of the model—that these different ways of representing the state of the window yield different causal verdicts. To illustrate, consider the following model $\boldsymbol{M 1}=\langle\boldsymbol{U 1}, \boldsymbol{V 1}, \boldsymbol{E} 1\rangle$, which models a rock being thrown at a window in the presence of a speck of dust that slightly perturbs the rock, such that:

$$
\begin{aligned}
& \text { U1 }=\{\text { Throw, Float }\} \text {, where } \\
& \text { Throw }=\begin{array}{r}
1 \text { iff the rock is thrown } \\
0 \text { iff the rock is not thrown }
\end{array} \\
& \text { Float }=\begin{array}{l}
1 \text { iff the dust is floating in the air } \\
0 \text { iff the dust is not floating in the air }
\end{array}
\end{aligned}
$$

V1 $=\{$ Rock, Dust, Window1 $\}$

Rock $=1$ iff the rock is flying through the air toward the window 0 iff the rock is not flying through the air toward the window

Dust $=1$ iff the dust is floating through the air toward the window

0 iff the dust is not floating through the air toward the window

Window $1=1$ iff the window shatters as it actually does 0 iff the window remains entirely intact

$\boldsymbol{E} 1=\{$ Throw $=1$, Float $=1$, Rock $=$ Throw, Dust $=$ Float, and Window $1=$ Rock\}

M1 generates the following disconnected causal graph:

$$
\begin{aligned}
& \text { Throw } \rightarrow \text { Rock } \rightarrow \text { Window1 } \\
& \text { Float } \rightarrow \text { Dust }
\end{aligned}
$$


In M1, Float does not cause Window1, and this is a way of representing the causal truth that the dust floating in the air rather than not floating in the air is not a cause of the window shattering as it actually does rather than remaining entirely intact. The speck of dust slightly perturbs the rock but does not make a difference as to whether the window shatters or remains intact.

But compare $M 1$ to $M 2$, in which we replace Window1 with Window2 and thus replace $\boldsymbol{V} \mathbf{1}$ with $\boldsymbol{V} \mathbf{2}=\{$ Rock, Dust, Window2 $\}$, while replacing $\boldsymbol{E} \mathbf{1}$ with the following:

$$
\begin{aligned}
& \boldsymbol{E} 2=\{\text { Throw }=1, \text { Float }=1, \text { Rock }=\text { Throw, Dust }=\text { Float } \text {, and Window } 2=((1 \text { iff } \\
& \text { Rock }=1 \text { and Dust }=0) \text { and }(0 \text { iff } \text { Rock }=0 \text { or Dust }=1))\}
\end{aligned}
$$

$M 2=<\boldsymbol{U} 1, \boldsymbol{V} 2, \boldsymbol{E} 2>$ generates the following connected causal graph, on which Dust is a causal parent of Window2:

$$
\begin{aligned}
& \text { Throw } \rightarrow \text { Rock } \rightarrow \text { Window2 } \\
& \text { Float } \rightarrow \text { Dust } \rightarrow
\end{aligned}
$$

In M2, Float does cause Window2, and this is a way of representing the causal truth that the dust floating in the air rather than not floating in the air is not a cause of the window shattering as it actually does rather than not shattering as it actually does. The speck of dust does make a slight difference to how the window shatters by slightly perturbing the rock.

So does the presence of the speck of dust cause the shattering of the window? It depends on which contrast one considers. So says the contrastivist, and the causal modeler agrees. The presence rather than the absence of the speck of dust makes no difference to whether the window shatters or remains intact, but it does make a difference to whether the window shatters as it actually does or shatters in a slightly different way. In short, the speck of dust makes no difference as to whether the window shatters but does make a difference to how the window shatters. The contrasts we consider for the fate of the window correspond to the choice between the models $\boldsymbol{M 1}$ and $M 2$ and yield different answers to the equivocal question of whether the presence of the speck of dust causes the shattering of the window. An account of causation that does not take in causal and effectual contrasts does not naturally fit the epistemology of causal modeling. ${ }^{28}$

\section{CONTRASTIVE CAUSATION IN THE LAW}

I now turn to causal judgments in the law to argue that the contrastive account of causation-as seen in Contrast-sheds light. I argue that causation

28. Causal models can also feature variables with more than two possible values. To fit such models one needs to extend the contrastive account to cover sets of causal contrasts $C^{*}$ and sets of effectual contrasts $E^{*}$. See Schaffer, Contrastive Causation, supra note 6, for further discussion. 
in the law requires specification of both the causal and the effectual contrast. Essentially, specification of the causal contrast as lawful conduct on part of the defendant is needed so that the right alternative gets assessed, and specification of the effectual contrast as the better outcome for the plaintiff is needed so that the right damages get assigned. ${ }^{29}$

I should note at the outset that my focus is on matters of liability in common law, in cases where the defendant's breach of duty must be shown to have caused the plaintiff's damages. Causation enters the law in many other places. For instance, even within matters of liability in common law there is the matter of contributory negligence in tort law, in which the defendant alleges that the plaintiff has causally contributed to her own damages. But I regard the cases under discussion as paradigmatic.

Note also that I consider mainly (but not exclusively) torts and use cases drawn from various U.S. and U.K. jurisdictions. I follow the widespread practice of assuming that a unified doctrine can be extracted from these cases. If this is a fiction, it at least might prove a useful fiction.

\section{A. Causal Contrasts in the Law}

\section{Lawful Conduct as the Causal Contrast}

Consider a straightforward case of negligence in which a lifeguard naps while a swimmer drowns. More carefully, suppose that the lifeguard has a duty of reasonable care and breaches her duty, which causes the swimmer to die (his death being an actionable damage falling within the scope of liability for such a breach). I am interested in the way we come to judge that the lifeguard's breach of duty causes the swimmer's death. In particular, assuming that our causal judgments involve comparisons between actual and hypothetical scenarios, exactly which hypothetical scenario do we consider?

One natural answer-which the sine qua non test might be thought to offer-is that we are comparing the actual scenario in which the lifeguard napped with a hypothetical scenario in which that napping did not occur. For the napping is the actual event that took place, and the sine qua non test tells us to suppose that the actual event did not occur. But this is uncontroversially the wrong answer for the law. For it may well be the case that the lifeguard, had she not napped, would merely have snuck off for a cigarette or failed to provide a reasonable standard of care in some other manner. Thus it may well be that in the hypothetical scenario in which the napping did not occur, the swimmer's drowning would still have occurred. But clearly the charge of negligence (which requires establishing causation) remains apt and could not be answered by showing that the

29. For other attempts to apply a (somewhat different) contrastive view of causation to the law, see Peter Lipton, Causation Outside the Law, in Jurisprudence: CAmbridge Essays 127-148 (Hyman Gross \& Ross Harrison eds., 1992); and Broadbent, supra note 5. I discuss these views in Section III.B. 
lifeguard would merely have snuck off for a cigarette if she had not napped. The lifeguard's lawyer cannot defend her by showing her to be even more generally negligent!

Of course the law does not really care that the lifeguard napped but only that she breached the standard of reasonable care. This is the tortious aspect of her conduct. So a second natural answer-applying the sine qua non test directly to the tortious aspect-is that we are comparing the actual scenario in which the lifeguard breached her duty with a hypothetical scenario in which the actual breach did not occur. But there are two problems with this answer. The first and minor problem is a metaphysical problem. For what in the world was the actual breach but the napping? The breach does not seem to be some additional event that occurred alongside the napping. Rather we seem merely to be dealing with two descriptions of one event, namely, what the lifeguard did at the time. So this second answer seems to collapse into the first bad answer. Or at least, to prevent the second answer from collapsing into the first, one needs to think either that the lifeguard engaged in two different actions (both a napping and a breaching) at the time or that causation does not relate events (Sec. I.A) but instead relates something more fine-grained, such as facts or aspects of events. ${ }^{30}$

The second and major problem with this second answer is that-even waiving the metaphysical concerns-it still gives the wrong answer for the law. For it may well be the case that the lifeguard, in the hypothetical scenario in which her actual breach of duty does not occur, would merely have committed some other alternative breach of duty in its stead. For there are many ways to breach a duty. Merely imagining the nonoccurrence of the actual breach is not equivalent to imagining the occurrence of no breach whatsoever (e.g., a scenario in which the lifeguard acts lawfully with respect to the duty at issue). Thus it may well be that in the hypothetical scenario in which the actual breach does not occur, the swimmer's drowning would still have occurred by means of an alternative breach of duty. But clearly the charge of negligence still stands even if the lifeguard would have merely committed some alternative breach of duty in place of her actual breach.

Overall it is crucial to mark the difference between the following two distinct hypothetical suppositions:

(i) the supposition that the actual breach of duty did not occur;

(ii) the supposition that no breach of duty whatsoever occurred.

Given that the tortious conduct is the actual breach of duty, running the sine qua non test on the tortious conduct yields only supposition (i).

I suggest that the right answer is that we are comparing the actual scenario with a scenario in which the lifeguard acts lawfully with respect to the duty at issue. The law needs supposition (ii). This is the answer that gets the causation 
right. If the swimmer would have survived in such a scenario, then the lifeguard's negligence is a cause of death; whereas if the swimmer would not have survived in such a scenario, then the tort of negligence fails on grounds that the element of causation is lacking. I do not mean to suggest that there is no way to understand the sine qua non test as delivering supposition (ii)on the contrary, I argue in Section II.C.1 that the contrastive account can undergird a workable sine qua non test that delivers supposition (ii) — but mean just to clarify that supposition (ii) is what is needed.

Similar hypothetical cases could be constructed concerning contracts or in criminal law. Thus consider a straightforward case of breach of contract in which a customer pays for delivery of furniture, but the dealer then sells the furniture off to another customer instead of delivering it. What actually transpired was that the dealer sold the furniture to the second customer. But it may well be that had he not sold the furniture to the second customer, he would still have failed to deliver the furniture to the first customer in some other way. The relevant hypothetical alternative that the court needs to consider in assessing causation for the customer's actionable damages is not merely the alternative in which the dealer does not commit that actual breach but rather the alternative in which the dealer properly honors the contract.

Or consider a straightforward case of homicide in which the cold-blooded killer beheads the victim. We might imagine that the killer, had she not beheaded the victim, would merely have committed the murder in some other way. The relevant hypothetical alternative that the court needs to consider in assessing causation for the victim's death is not merely the alternative in which the killer does not commit that actual murder but rather the alternative in which the killer properly leaves the victim in peace.

Generalizing, it seems that causal judgments in the law are based on a comparison between the actual course of events and an alternative scenario in which the defendant acts lawfully. In light of these examples, I am proposing the following:

(Causal Contrast in the Law) Causation in the law is best understood as involving a causal contrast $c^{*}$, which is specified as lawful conduct ${ }^{31}$

To the lawyer, this might seem like stating the obvious. My point is not that the lawyer is picking up on the wrong hypothetical alternative but rather that

31. The appeal to lawful conduct is hardly new. For instance, HART \& HONORÉ, supra note 3, at lx, speak of assessing causation by constructing a hypothetical "parallel series," and comment, "the parallel series is constructed by asking what the course of events would have been had the defendant acted lawfully." Likewise, Stapleton, supra note 5, at 448, speaks of the law as providing "filtering devices" that "specify relevant hypothetical comparator worlds" where "the specified factor in turn determines the hypothetical worlds (because these are no-breach worlds)." Id. at 450. I am arguing that a contrastive approach is the best way to implement this insight. 
the lawyer is rightly picking up on a very particular hypothetical alternative and could clarify her causal discourse by being explicit about it.

The appeal to lawful conduct is an appeal to a causal contrast $c^{*}$. The standard template of " $c$ causes $e$ " simply does not encode enough information since it does not yet tell us which alternative scenario to consider. For instance, from the fact that a given individual took a light nap $(c)$, one cannot yet tell what alternative scenario to consider in evaluating causal impact. The neuroscientist might be interested in the alternative scenario in which the person went into a deeper sleep state, because she might be interested in the different brain outcomes associated with light versus deep sleep. The lawyer might be interested in the alternative scenario in which the person attempted to rescue a swimmer because she might be interested in establishing causation in a tort of negligence against a napping lifeguard. Those working with the " $c$ causes $e$ " template tend to look at alternative scenarios in which $c$ does not occur, since this alternative is a function of $c$. But the supposition that the defendant acts lawfully is not the same supposition as the supposition of the actual event or breach in question not occurring, since the latter supposition allows the defendant to act unlawfully in nonactual ways. The supposition that the defendant acts lawfully is a specific supposition about the causal contrast which is of special interest to liability judgments in the law. It is not a function of $c$ but represents new information.

The law achieves this specification of the causal contrast $c^{*}$ in part by describing actual events in very particular ways, namely as breaches of duty. For instance, in describing what the lifeguard actually did as a breach of duty, we implicitly contrast what she actually did (napping) with the lawful course of conduct in which she fulfills her duty of care. The neuroscientist interested in light versus deep sleep might choose to describe what the lifeguard actually did as "light sleeping." In this sense, describing the lifeguard's napping as a breach of duty is akin to describing the gardener's drinking at the pub as a failure to water my flowers. In both cases the description serves to denote an actual event (a napping, a drinking) while making relevant a specific contrast (dutiful lifeguarding, watering my flowers). Indeed, with respect to the cases under discussion, the law hardly cares that the lifeguard napped and that the gardener drank, it cares only that each departed from the lawful course. The point of describing events in terms of duties breached (as the laws of liability describe them) is to introduce implicit comparisons to a specified alternative. The contrastive account would merely make this explicit and thus illuminate the role of event descriptions in causal discourse.

In summary, I am making three main points in this section. First, causal judgments in the law involve comparing the actual course of events with the course of events in the hypothetical scenario in which the defendant acts lawfully. Second, the content of the hypothetical scenario in which the defendant acts lawfully cannot be derived merely from what the defendant actually did $(c)$ but needs to be independently specified as a causal contrast 
$\left(c^{*}\right)$. Third, the law (in liability contexts) achieves this specification through descriptions of what the defendant actually did in terms of departures from the lawful course. This is how the language of "breach of duty" feeds into our causal judgment.

\section{Lawful Conduct Clarified}

But what exactly is lawful conduct? As Hart and Honoré acknowledge upon introducing the notion, it "needs to be spelled out more fully." ${ }^{22}$ I should caution at the outset that the law comes to us as a work in progress, not as a completed document of perfect clarity. So, while there are respects in which I think it is possible to clarify the notion of lawful conduct further, one should expect the notion to remain somewhat open-ended. Indeed, I think some of the most interesting case law arises out of the open-endedness of this notion. Part of the point of an explicitly contrastive approach to causation in the law is to help reveal what is at issue in these hard cases.

There are at least three respects in which it is possible to clarify the notion of lawful conduct further. First, what counts as lawful conduct is relative to a given duty, namely the one that the defendant is charged with breaching. On this point the plaintiff calls the shots. The plaintiff issues a charge of a specific breach, which lawful conduct is assessed against. For instance, if the plaintiff complains that the defendant was breaching her duty to drive reasonably within the speed limit, then the breach in question is failing to meet the standard of driving reasonably within the speed limit. Lawful conduct is thereby specified as driving reasonably within the speed limit. In order to establish causation with respect to this complaint, the plaintiff would need to consider the alternative scenario in which the driver drove reasonably within the speed limit, and the question of causation would then-quite properly-turn on the question of what would happen in that alternative scenario. In this vein, Hart and Honoré rightly say:

If the defendant acted unlawfully by performing a lawful act in a forbidden manner, e.g., by driving above the speed limit, we must ask what would have happened had he driven at a reasonable speed. The proper hypothesis is not that he drove marginally within the speed limit, nor that he refrained from driving altogether. ${ }^{33}$

It is crucial to appreciate that other lawful alternatives-for instance the alternative in which the defendant merely stays home and watches television the whole evening-are rendered irrelevant by the plaintiff's complaint. Of course the plaintiff could try to access this alternative by describing

32. Hart \& HonOré, supra note 3 , at lx. Indeed, Broadbent, supra note 5 , at 188 , rightly criticizes some of my earlier comments on contrastive causation in the law for failing to "tell us exactly how contrasts are picked." What follows is an attempt to do better!

33. HART \& HONORÉ, supra note 3 , at lx. 
the defendant's breach as a breach of his duty to stay at home and watch television the whole evening, but evidently there is no such duty (at least in the normal case).

To put this first point another way, causal judgment in the law (where liability is concerned) generally takes place in a context in which the defendant has been charged with breaching a specific duty. What is at issue is whether this breach causes the actionable damages to the plaintiff. I am claiming that lawful conduct - what serves as the causal contrast $c^{*}$ in causal judgments in the courtroom-is determined in part by this aspect of the context.

The case of McWilliams $v$. Sir William Arrol $\mathcal{E}^{2}$ Co. Ltd. ${ }^{34}$ provides a useful illustration of the way in which the plaintiff's charge of a specific breach feeds into causal considerations. In this case, the employers of a steelworker failed to provide a safety belt, and the worker fell off a tower to his death. The employer was sued, with the breach specified as a failure to provide a safety belt. But it was decided on the evidence that the worker would probably not have worn a safety belt had one been provided, and so it was held that the plaintiff failed to prove causation. Yet had the complaint been that the employer both failed to provide a safety belt and failed to establish a workplace system that prevented employees without belts from ascending the tower, then causation might well have been established. ${ }^{35}$

The reason these different complaints would lead to different causal judgments about one and the same actual event is that they institute different causal contrasts $c^{*}$. Relative to the first complaint, we look at hypothetical scenarios in which the employer merely provides safety belts, and predict that the worker still winds up dead. But relative to the second complaint, we look at hypothetical scenarios in which the employer both provides safety belts and ensures they are worn, and predict that the worker survives.

Second, what counts as lawful conduct relative to a given duty is minimal compliance with this duty. Here I am in disagreement with Hart and Honoré, who say: "What ['acting lawfully'] means is that the defendant must be taken to have acted exactly as he did except that he conformed to the law to the full extent that a lawful and reasonable person would have done, not just minimally." 36 The needed corrective is found in Stapleton:

Suppose a motorist is speeding at $60 \mathrm{mph}$ in breach of his duty to abide by a $50 \mathrm{mph}$ speed limit, he skids and is unable to recover control of his vehicle before it hits V. The Law determines what would have been the highest speed a reasonable person would have been going in the circumstances, say $45 \mathrm{mph}$. When the Law considers what the fate of $\mathrm{V}$ would have been in the hypothetical no-breach world, the defendant's behavior is altered just enough to bring it

34. McWilliams v. Sir William Arrol \& Co. Ltd., [1962] 1 All E.R. 623.

35. Cf. Stapleton, supra note 5 , at 450 .

36. HART \& HonORÉ, supra note 3 , at lx. 
into conformity with his duty as mandated by the Law, namely $45 \mathrm{mph}$. To test whether the motorist's breach was involved by a connection of necessity in V's being injured in the way he complains about, we ask whether the motorist would have skidded and hit $\mathrm{V}$ had he been driving at $45 \mathrm{mph}$ and, if so, which injuries $\mathrm{V}$ would have suffered. ${ }^{37}$

Why do Hart and Honoré suggest that minimal compliance is not enough? I think they may be confusing speeding with negligence for driving at an unreasonable speed. ${ }^{38}$ When one is driving in a 50 m.p.h. zone, one has multiple duties. One has the duty not to speed, minimal compliance with which allows one to drive at any speed up to and including 50 m.p.h. As long as one is in minimal compliance with the speed limit, one is not speeding. One also has the duty of driving at a reasonable speed. Minimal compliance with this duty will depend on the traffic, weather, and other conditions. But under certain road conditions, minimal compliance with the duty to drive at a reasonable speed might only allow one to drive 45 m.p.h. In that case minimal compliance with the duty to drive at a reasonable speed allows one to drive no faster than 45 m.p.h. What makes 45 m.p.h. the legally mandated speed-relative to a tort of negligence in which the plaintiff has specified the breach as driving at an unreasonable speed-is not that $45 \mathrm{mph}$ is reasonably within the bounds of the speed limit but rather that it is minimally within the bounds of the reasonable speed given the circumstances.

Above I am clarifying that lawful conduct involves minimal compliance with the specific duty that the defendant has been charged with breaching. I use the example of a tort of negligence (with respect to the duty to drive at a reasonable speed) to show how we recover the idea that the specific alternative the law considers is one in which the defendant drives in a specific way (e.g., 45 m.p.h.). But this example has a special feature: it permits only one way to comply. In other cases, the law permits multiple courses of conduct to a minimally compliant person relative to a given duty. For instance, in Haft v. Lone Palm Hotel, ${ }^{39}$ the owners of a hotel with a swimming pool could have discharged their safety obligations either by posting a warning sign near the pool or by hiring a lifeguard. Both would have been lawful, reasonable, and compliant courses of conduct. They did neither, and a father and his son who had been staying at the hotel drowned in the pool. Yet it matters which alternative course of conduct one considers, since posting a warning sign probably would not have made any difference (few heeds such signs),

37. Stapleton, supra note 5 , at 451.

38. Speeding is a conduct offense against a statutory duty in the public law and does not involve any claim of damages nor any causal element. Negligence for breaching the duty of driving at a reasonable speed concerns the private law of torts and requires a claim of damages and the establishment of a causal connection between the breach and the damages. One can be driving under the speed limit (and thus not speeding) while still driving at an unreasonable speed (and thus negligent), for instance if there is heavy traffic or the road is icy.

39. Haft v. Lone Palm Hotel, 3 Cal. 3d 756, 478 P.2d 465, 91 Cal. Rptr. 745 (1970). 
while hiring a lifeguard would probably have prevented the deaths. So the third respect in which it is possible to clarify the notion of lawful conduct further is that the law still needs to decide how to resolve cases with multiple options open.

The finding in Haft was that the negligence of the hotel owners did not cause the deaths, since the hotel owners could have discharged their duties by posting a warning sign, which would not have helped. Here it seems that where the law allows multiple distinct courses of conduct, it should be satisfied by any of them.

To put this third point another way, Haft suggests that where there are multiple minimally compliant causal contrasts ${c_{1}}^{*}, c_{2}{ }^{*}, \ldots$, the defendant calls the shots. She gets to select a contrast from among the options the law allows her. Thus in Haft, there are two minimally compliant causal contrasts: $c_{1}{ }^{*}=$ the owners post a warning sign, and $c_{2}{ }^{*}=$ the owners hire a lifeguard. The harm at issue is the drowning of the father and son. Plugging in Test for each of these causal contrasts, it is reasonable to assume that $c$ rather than $c_{2}{ }^{*}$ causes the father and son to drown rather than survive (a lifeguard would have saved them). But it is reasonable to assume that $c$ rather than $c_{1}{ }^{*}$ has no causal impact on the father and son (they would have ignored the sign anyway). The defendant gets to select $c_{1}{ }^{*}$ as the relevant contrast and thereby can establish that the element of causation is missing. ${ }^{40}$

Putting these three points of clarification together, I am proposing the following:

(Lawful Conduct) Lawful conduct with respect to the breach of duty alleged by the plaintiff is minimal compliance with this duty in a form selected by the defendant

And so Causal Contrast in the Law takes on further substance, insofar as the notion of lawful conduct that it embeds is further detailed. Vagaries remain, but such is to be expected. Where matters are left open, the law may have recourse to general fallback principles, such as Hart and Honoré's point that "the aim of the legal system is to secure conformity to certain standards of conduct." 41 In other cases matters may simply need to get decided. (I leave open what general background considerations can and should guide the law.)

40. There is a worry that this might give the defendant too much leeway in allowing her to specify some highly detailed but improbable lawful course of conduct that would have been the one course of conduct that would not have made a difference. There may be some interaction with reasonable forseeability at this point. The law may also characterize the available courses of conduct quite coarsely, so it may filter out the use of very detailed courses of conduct by limiting which values of $c^{*}$ the defendant can choose between. For instance, in Haft it seems as if the defendant is limited to choosing between $c_{1}{ }^{*}=$ the owners post a warning sign, and $c_{2}{ }^{*}=$ the owners hire a lifeguard.

41. HART \& HonORÉ, supra note 3, at lx. 
B. Effectual Contrasts in the Law

\section{Better Outcome as the Effectual Contrast}

Just as the law needs to specify a causal contrast to ensure that the right alternative scenario gets assessed, so the law also needs to specify an effectual contrast to ensure that the right damages get assigned. The sine qua non test asks whether the actual outcome $e$ in which the plaintiff suffers the actionable damages would still have occurred. But such a question is blind to distinctions among alternative non- $e$ outcomes. One possibility is that $e$ would have been replaced by an alternative outcome in which the plaintiff met a better fate, but another possibility is that $e$ would have been replaced by an alternative outcome in which the plaintiff met an equal or even worse fate. Only in the former case does the occurrence of $e$ constitute damage. The law needs a conception of causation that distinguishes between such non- $e$ outcomes by specifying the effectual contrast $e^{*}$.

For instance, suppose that a broker attempts to offer fraudulent financial advice, on the basis of which his client loses one million dollars. That is, suppose that the broker knowingly and for his own personal gain misrepresents a potential investment to his client, who rightly and in ignorance relies on this misrepresentation and as a result comes out losing one million dollars. It might seem as though all of the elements of fraud are in play. But wait! I have said that the client comes out losing one million dollars in the actual outcome, but I have not yet said how she would have fared in the hypothetical scenario in which the broker properly represented the investment. Perhaps in that hypothetical scenario she would have lost five million dollars instead. The law needs a conception of causation that distinguishes between the various alternative outcomes to her loss of one million dollars. For all the elements of fraud to be in play, the broker's misrepresenting the investment rather than properly representing it must cause the client to lose one million dollars rather than meet a better outcome. If the plaintiff cannot establish the prospect of a better hypothetical outcome, she cannot establish fraud.

Or suppose that Jones, practicing medicine without a license, performs surgery on Smith, and Smith then dies. Again it might seem as though all of the elements of liability are in play. But wait! I have said that Smith dies, but I have not yet said how he would have fared in the hypothetical scenario in which Jones practiced properly. Perhaps Jones, due to sheer good luck, actually managed to prolong Smith's life a day beyond what standard medical care could be expected to accomplish. We need to go beyond what is explicit in the sine qua non test in order to distinguish causing someone to die on Tuesday rather than Monday from causing someone to die on Tuesday rather than Wednesday. ${ }^{42}$ 
Overall it is crucial to mark the difference between the following two distinct notions of damages:

(i) damages as the actual outcome;

(ii) damages as the comparison between the actual outcome and a hypothetical better outcome.

When we ask whether the damages are actionable, we are concerned with the actual outcome as per (i) and are interested in the question of whether it is the type of outcome that one can complain about in the courtroom. But when we ask whether there were damages, we are concerned with the comparative notion as per (ii) and are interested in the question of whether the defendant's breach of duty rendered the plaintiff worse off. So in the unlicensed doctor case, there are actionable damages in the sense that the actual outcome (Smith's death) is the type of outcome that can be complained about. But there are no damages in the sense that comparatively Smith was no worse off (in fact he benefited).

Generalizing, it seems that the causal element of liability requires showing a causal connection between the defendant's breach of duty and the damages, understood in the comparative sense of (ii). Thus I am proposing the following:

(Effectual Contrast in the Law) Causation in the law is best understood as involving an effectual contrast $e^{*}$, concerning a comparatively better outcome for the plaintiff

The crucial point is this: the supposition that the actual outcome e did not occur is not the same supposition as the supposition that a better outcome $e^{*}$ would have occurred. Sometimes the effect in question is merely replaced with a different outcome that is equal or worse for the plaintiff. The law needs to find that the defendant's breach made the difference between the actual outcome and a better outcome for the plaintiff in order to say that the plaintiff has really suffered (comparative) damages as a result of the breach.

Indeed, the very notion of damage or harm-which defendant's breach must be shown to cause- - has an implicitly contrastive reading. Just as speaking of an actual event as a breach of duty is a way to contrast it implicitly with lawful conduct (Sec. II.A.2), so speaking of an actual outcome as harm or damage is a way to compare it implicitly with a better alternative. The law thus achieves the specification of $e^{*}$ through descriptions of the actual outcome in terms of comparative damage. For instance, in the fraudster broker case, if the client actually comes out losing one million dollars but would have lost only eight hundred thousand dollars had the broker acted lawfully, then the damages will properly be described as a loss of two hundred thousand dollars. Such a description encodes a comparison between the actual outcome (one million dollars) and the hypothetical outcome (eight hundred thousand dollars). 
Indeed, the specification of $e^{*}$ is not only needed to determine whether there have been comparative damages, it also comes back into play later when liability is quantified. The case of Dillon v. Twin State Gas E् Electric $\mathrm{Co}^{43}$ provides a useful illustration of this principle. In Dillon, a boy lost his balance while climbing on a bridge. In an effort to avoid falling to his death, he grabbed some electrical wires. But these wires had negligently been left exposed, and so the boy was electrocuted. The judgment in Dillon was that the electrical company satisfied all the elements of liability for the actionable damage of the boy's death. They had a duty to insulate the wires, breached the duty, and this breach caused the boy to be electrocuted (which outcome falls within the scope of liability). But when it came to quantifying this liability, the quantum was held to be minimal (corresponding to the few seconds of life the boy had lost), since the boy was "dead either way." 44

On the standard reading, what happens in Dillon is that the electrical company's negligence is first shown to have caused the boy's death, and only then (postcausally) does the quantification of liability take place. Thus Moore comments on this case: " $[\mathrm{I}] \mathrm{n}$ tort law when we kill one of the almost dead ... his life is valued at a fraction of the life of one with a normal life expectancy." ${ }^{45}$ This reflects the standard idea that we have already established causation of death (killing), and only then does the value of the life come into consideration. At this point a comparison with an alternative outcome comes into play, in a way that Stapleton makes explicit: "The boy's prospects are, of course, relevant to how much the company will have to pay in damages because this 'valuation' of the claim is calculated in relation to how the long the boy would have lived had no tort been committed against him." ${ }^{46}$ I am adding that the earlier specification of $e^{*}$ when the causal connection was established, is helping guide the later quantification of liability.

So on the contrastive view, the actual causal connection found in Dillon is: the electrical company's leaving the wires uninsulated $(c)$ rather than insulating the wires $\left(c^{*}\right)$ caused the boy to be electrocuted $(e)$ rather than alive but in free fall toward the bottom of the ravine $\left(e^{*}\right)$-and thus dead either way. The alternative outcome $e^{*}$ is a crucial aspect in the quantification of liability. What I think is especially plausible about this approach is the way it connects the causal element of liability with the later stage of quantification. This helps tighten the connection between what the defendant did and what she owes.

In summary, I am making four main points in this section. First, causal judgments in the law involve comparing the actual outcome with a hypothetical outcome in which the plaintiff would have fared better. Second,

43. Dillon v. Twin State Gas \& Electric Co., 85 N.H. 449, 163 A. 111 (1932).

44. Crucial to this judgment is the legal idea that being in free fall toward the bottom of a ravine leads naturally to death, unlike in a standard preemption case, where the victim may be "dead either way" but only via the intervening hand of a second agent.

45. MoOre, supra note 2 , at 68.

46. Stapleton, supra note 5 , at 452 . 
the outcome in the hypothetical scenario in which the plaintiff would have fared better cannot be derived merely from the actual outcome $(e)$ but needs to be independently specified as an effectual contrast $\left(e^{*}\right)$. Third, the law (in liability contexts) achieves this specification through descriptions of the actual outcome in terms of comparative damage, which is an implicitly comparative notion. Fourth, the hypothetical outcome comes back into consideration when liability is quantified, in ways that help tether the initial judgment of liability to its later quantification.

\section{Better Outcome Clarified}

But what exactly is the better outcome? It would help to be more precise about this notion-though again, I should caution that the law is a work in progress, and so one should not expect every possible detail to come prejudged (Sec. II.A.2). There will be hard cases. Part of the point of an explicitly contrastive approach is to help illuminate why these cases are hard.

There are at least three respects in which it is possible to clarify the notion of a better outcome further. First, what counts as the alternative outcome must be assessed and valued at the time of the actual outcome, not later. A useful illustration of this principle may be seen in the case of The London Corporation. ${ }^{47}$ In London Corp., two steamships-the Benguela and the London Corporation - collided, damaging the Benguela. It was agreed that both parties shared blame. The owners of the Benguela (the plaintiffs) sued for damages amounting to the cost of repairs, while the owners of the London Corporation (the defendants) argued that no such loss was suffered since no repairs were made-the owners of the Benguela in fact went on to sell their ship for scrap in an unrepaired state.

The finding in London Corp. was for the plaintiff, for the cost of repairs. The fact that the Benguela was later scrapped was considered an accidental circumstance not to be factored into the harm. In the contrastive framework, this amounts to the idea that the effect $e$ is the Benguela being in the damaged state at the time just after the collision, while $e^{*}$ is the Benguela maintaining its previous undamaged state at that time. In quantifying liability, we assign values to the $e$ and $e^{*}$ states and compare. We do not look at accidental circumstances beyond this time, such as whether or not any repairs were carried out later.

Second, what counts as the alternative outcome must be assessed while holding other relevant factors fixed (to the extent compossible with imagining that the defendant acted lawfully). This is standard in the evaluation of counterfactuals and may be usefully illustrated by the case of Bolitho v. City and Hackney Health Authority. ${ }^{48}$ In Bolitho, a child was brought to a hospital with breathing difficulties due to croup. While in the hospital, the child's condition worsened, and the nurse notified the doctor. But the doctor

47. The London Corporation, [1935] 51 Ll.L. Rep. 67.

48. Bolitho v. City \& Hackney Health Auth., [1997] 4 All E.R. 771. 
failed to attend to the child. The child then suffered complete respiratory blockage, leading to his eventual death. It was concluded that the doctor had been negligent in failing to attend to the child, and so it remained to decide whether the doctor's negligence caused the death. It was also concluded that had the doctor properly attended to the child (the lawful course), medical practice allowed for two courses of treatment, one involving intubating the child, and the other not involving intubation. ${ }^{49}$ Only intubation would have saved the child. But that still did not settle the case. What settled the case in Bolitho was evidence that the doctor, had she attended to the child, would herself not have chosen to intubate. This was the grounds for the decision-in favor of the defendant - that the negligence of the doctor did not cause the child's death. We hold fixed the doctor's general tendencies of treatment (in this case not intubating) in filling in the hypothetical scenario. (So, presumably, had the evidence been that this doctor usually intubated in such situations, then the judgment would have gone to the plaintiff. In that alternative version of Bolitho, the causal element of negligence would have been in place, even though a doctor could still have discharged her duties without saving the child.)

Third, what counts as the alternative outcome cannot always be associated with what would follow from the supposition $\left(c^{*}\right)$ that the defendant acted lawfully because of cases of redundant causation (Sec. I.A). Where there is no redundant causation, the alternative outcome $\left(e^{*}\right)$ can usually be identified with the counterfactual entailment from lawful conduct $\left(c^{*}\right)$ in accord with Test. But where there is redundant causation, we need to consider the possibility that $c$ rather than $c^{*}$ causes $e$ rather than $e^{*}$, even though $e$ would still have occurred in the alternative $c^{*}$ scenario due to the presence of a redundant causal factor. For instance, in the event that two gunmen independently fire a fatal shot at a single victim, the law will judge that each individual gunman has acted so as to cause death. ${ }^{50}$ That is, gunman 1's shooting at victim $(c)$ rather than holding fire $\left(c^{*}\right)$ causes the victim to die $(e)$ rather than survive $\left(e^{*}\right)$ - even though had gunman 1 held fire, the victim would still have died due to the intervening action of gunman 2 .

What is crucial to the proper handling of redundant causation cases is simply that we appreciate that there is causation involved and what the effectual contrast is for such causation. This allows the law to get the right result, namely that gunman 1's shooting causes the victim's death. We can help ourselves to the natural idea of causal relatedness and say that the alternative outcome can be associated with what was causally prevented by the occurrence of $c$ rather than $c^{*}$. (I should reiterate that I am not attempting

49. There was disagreement among the medical experts testifying as to whether a competent doctor would have intubated, which established (as per Bolam v. Friern Hosp. Mgmt. Comm., [1957] 1 W.L. 583) that not intubating was in accord with at least one body of expert opinion and so was nonnegligent.

50. Cf. Tony Honoré, Causation in the Law, in STANFord EnCyClopedia OF PHILOSOPHY (2010), available at http://plato.stanford.edu/entries/causation-law/. 
an analysis of causal relatedness here. Rather I am relying on an intuitive understanding of causal relatedness to argue that there are four causal relata in the roles of cause, causal contrast, effect, and effectual contrast [Sec. I.A].) For instance, gunman 1's shooting at the victim rather than holding fire still causes the victim to die rather than survive because the victim's survival (the alternative outcome) was causally prevented by the gunman's shooting instead of holding fire. This causal claim is true despite the presence of gunman 2, who also causally prevented the victim's survival. Redundant causation is a severe problem for any would-be reductive analysis of the causal relation. But I am not attempting any analysis and so can describe redundant causation in causal terms.

Putting these three points of clarification together, I am proposing the following:

(Better Outcome) The better outcome with respect to the damage suffered by the plaintiff is the alternative outcome assessed at the time of the actual outcome, holding fixed other relevant factors, and causally prevented by the defendant's breaching duty rather than acting lawfully

And so Effectual Contrast in the Law takes on further substance insofar as the notion of the better outcome that it embeds is further detailed. As with Lawful Conduct (Sec. II.A.2), some vagueness is to be expected. Where matters are left open, the law may have recourse to general fallback principles, or matters may simply need to get decided.

\section{Underneath the Sine Qua Non and NESS Tests \\ 1. Underneath the Sine Qua Non Test}

The contrastive treatment of causation in the law is intended not as a revisionary proposal but rather as a description of actual practice. The point is not to change the law but to interpret it. Actual practice often involves use of the sine qua non test. But the test is not used in a straightforward way, or else the law would not reach the judgments it reaches in the cases discussed above (Secs. II.B-II.C). Rather the test is used in an implicitly contrastive manner. The supposition of the cause not occurring is interpreted as the supposition of the causal contrast occurring, and the supposition of the event not occurring is interpreted as the supposition of the effectual contrast occurring.

To see how contextually variable the general nonoccurrence suppositions of the official sine qua non test are, compare the following three negated occurrence suppositions (where italics represent phonological stress of the sort associated with focus):

(i) If John had not kissed Mary ... ;

(ii) If John had not kissed Mary ...;

(iii) If John had not kissed Mary. . . . 
Supposition (i) is naturally read as supposing that someone else (perhaps Tom) kissed Mary; (ii) is naturally read as supposing that something else (perhaps a chaste handshake) transpired between John and Mary; while (iii) is naturally read as supposing that John kissed someone else (perhaps Tom).

Indeed, perhaps the most natural interpretation of these focal differences is as contrastive differences. ${ }^{51}$ Thus compare (i) through (iii) to their following respective counterparts:

(i) If Tom rather than John had kissed Mary ...;

(ii) If John had shaken hands with rather than kissed Mary ...;

(iii) If John had kissed Tom rather than Mary....

Thus to rely on intuitive readings of negated occurrence suppositions is to rely on implicit contrastivity. The negated occurrence suppositions are read as the contextually relevant alternatives. The sine qua non test is thus implicitly causally contrastive, as per Causal Contrast in the Law.

Similar issues arise with respect to general nonoccurrence suppositions concerning the effect. Thus compare the following three negated occurrence suppositions:

(i) ... then John would not have kissed Mary;

(ii) ... then John would not have kissed Mary;

(iii) ... then John would not have kissed Mary.

Again these suppositions are naturally interpreted contrastively. They may be usefully compared to:

(i) ... then Tom rather than John would have kissed Mary;

(ii) ... then John would have shaken hands with rather than kissed Mary;

(iii) ... then John would have kissed Tom rather than Mary.

The sine qua non test is thus implicitly effectually contrastive as well, as per Effectual Contrast in the Law. I thus conclude that Contrast is not an alternative to the sine qua non test, but rather provides the theoretical basis for it, as per the following:

(Contrastive Sine Qua Non) When the sine qua non test is used in the law, the supposition of the cause not occurring is interpreted as the supposition of the causal contrast occurring, and the supposition of the effect not occurring is interpreted as the supposition of the effectual alternative occurring

51. In this vein, Mats Rooth, A Theory of Focus Interpretation, 1 Nat. Language Semantics 75116 (1992), proposes the alternative semantics approach to focus. On Rooth's treatment, focus adds a semantic marker whose value is a contextually determined set of alternatives. So "John kissed Mary" gets semantically interpreted as [[John $]_{F}[$ kissed Mary] $]$, where [John $]_{F}$ induces a dual interpretation, one of which is John, and the other of which are the salient alternatives (e.g., Tom). Where focus is semantically effective, it is because contrasts are semantically operative. 
When Moore criticizes the sine qua non test, he rightly notes that the supposition of the cause not occurring is highly indeterminate: "We know we are to eliminate the defendant's act, but what are we to replace it with ...? To make the counterfactual test determinate enough to yield one result rather than another, we have to assume that we share an ability to specify some definite possible world." ${ }^{22}$ Contrastive Sine Qua Non explains how Moore's theoretical indeterminacy is resolved in practice. When the law considers claims of the form "but for the breach ....," what actually gets considered is the specific supposition of lawful conduct in place of the breach.

As David Lewis notes by way of motivating a counterfactual dependence account of causation: "We think of a cause as something that makes a difference." ${ }^{53}$ Only Contrast takes this difference-making idea literally, since only Contrast articulates what the differences are: $c^{*}$ and $e^{*}$. I am arguing that the law builds on this idea in a particular way, taking $c^{*}$ to be lawful conduct and $e^{*}$ to be the comparison outcome. Causal judgments in the law are contrastive judgments.

\section{Underneath the NESS Test}

Another test invoked in more recent theorizing as an improvement to the sine qua non test is the necessary element of a sufficient set (NESS) test. The NESS test is related toJ.L. Mackie's account of causation and developed and applied to legal situations by Richard Wright. ${ }^{54}$ To apply the NESS test, one needs (i) to find a set of actual factors $S$ such that $c \in S$ and $S$ is sufficient for $e$, and (ii) to show that $c$ is a necessary element for the sufficiency of $S$ by showing that $S\{\{c\}$ is insufficient for $e$. The NESS test is advertised as agreeing with the sine qua non test where there is only a single set of actual factors sufficient for $e$ but as doing better in redundant causation cases where there are multiple sets of sufficient factors for $e$.

I want to separate the question of whether the NESS test in fact provides a fully adequate account of causal relatedness from the question of whether the NESS test relies on implicit contrastivity. I am interested in only the second of these questions. Whether or not the NESS test in fact provides a fully adequate account of causal relatedness, I think that there should be little dispute that it is an excellent test. My claim is that the NESS test relies on implicit contrastivity. ${ }^{55}$

The first question that must be asked of the NESS test is what it means to speak of a set of conditions $S$ as "sufficient" for a given outcome $e$. Wright

52. MoORe, supra note 2 , at 85 .

53. LEWIS, supra note 10, at 160-161.

54. J.L. MACKIE, The Cement of the Universe (1974); Wright, supra note 25.

55. See Fumerton \& Kress, supra note 8 , for a detailed critique. I am in sympathy with Judith Jarvis Thomson, Some Reflections on Hart and Honoré, in CAUSATION IN THE Law. The Legacy of H.L.A. Hart: Legal, Political and Moral Philosophy 143-164 (Matthew H. Kramer, Claire Grant, Ben Colburn, \& Anthony Hatzistavrou eds., 2008), at 150, who reviews the many positive features of the NESS account, and then says: "It is therefore unfortunate that there are serious objections to the analysis," such as preemption cases ( $c f$. Fumerton \& Kress, supra note 8, at 89; Stapleton, supra note 5, at 471-480). 
explicitly intends a nomological rather than a counterfactual conception of sufficiency. He is interested in whether there is a causal law linking $S$ to the outcome $e$. The second question that must be asked of the NESS test is what it means to speak of a given factor $c$ as "necessary" for the sufficiency of $S$. Wright explicitly has in mind the idea that $S\{c\}$ would be insufficient for $e^{56}$

That clarified, the first place where the NESS test seems to me to rely on implicit contrastivity is in its characterization of the necessity of a factor for the sufficiency of a sufficient condition. Wright assumes that $S-\{c\}$ will have determinate lawful consequences. But the lawful consequences of $S-\{c\}$ depend on what $c$ is replaced with. For instance, if we take the case where the cold-blooded killer beheads the victim, we need to know whether the beheading is being replaced by a rift in the fabric of space-time, a vacuum where nothing occurs, a peaceable hug between killer and victim, or merely a numerically different assault (inter alia). These will have drastically different lawful consequences.

What Wright must do, it seems to me, is not to assess the lawful consequences of an incomplete situation $S-\{c\}$ (as there are no such consequences) but rather to assess the lawful consequences of a complete situation $S^{*}$, where $c$ is replaced by a specific alternative $c^{*}$. Indeed, I think this is what he implicitly does. He does so via his insistence that $c$ be characterized as the tortious aspect of the conduct. As he puts the point:

The description of the tortious (or negligent) conduct must include those aspects of the conduct which made it tortious (or negligent)-e.g., leaving a loaded gun lying around, sitting on an unstable wall, or standing on the unrailed portion of a platform. ${ }^{57}$

The above italics encode the implicit contrastivity in the description. To assess the necessity of leaving a loaded gun lying around for the sufficiency of a sufficiency set $S$, one should assess the lawful consequences of $S^{*}$, in which an unloaded gun is imagined to have been left lying around instead. And so the causal contrast finds its way into the NESS test. We should at least be explicit about this.

The second place where I think that the NESS test relies on an implicit contrastivity-this time that of the effectual contrast-is in its characterization of the sufficiency of a set of factors for a given outcome. For saying that $S$ is sufficient for $e$ means that we would have insufficiency if the causal laws instead linked $S$ to any non- $e$ outcome. But as such the explicit formulation of the NESS test fails to distinguish the cases where $S$ fails to be sufficient by being linked to a better outcome than $e$ or by being linked to

56. Wright, supra note 24 , at 1102-1103.

57. Id. at 1084 . 
an equal or worse outcome. It does not distinguish between various non- $e$ outcomes. For instance, it may well be that the misrepresentation of the fraudster broker is part of a set of actual conditions $S$ that are sufficient for his client to lose one million dollars. But we need to distinguish the case where $S^{*}$ - the hypothetical conditions that include the broker offering a proper representation-lawfully entails the client losing eight hundred thousand dollars from the case where $S^{*}$ lawfully entails the client losing five million dollars. For only in the first case has the client suffered damages in the relevant comparative sense (Sec. II.B.1).

Hence I conclude that Contrast is not an alternative to the NESS test but rather implicitly guides the NESS test, as per the following:

(Contrastive NESS) When the NESS test is used in the law, what is considered is whether $S^{*}$ (the result of replacing the cause $c$ in the sufficiency set $S$ with the causal contrast $c^{*}$ ) lawfully entails the effectual contrast $e^{*}$

For instance, to determine whether the broker's misrepresentation passes the NESS test for the client's damages, we need to consider the lawful consequences of the set of actual factors with the replacement of a proper representation to find out whether these lawfully entail a better outcome for the defendant.

I should reiterate that I am not attempting any criticism of the sine qua non or NESS tests. I think these are (at the very least) excellent tests. I am trying only to show how they are not alternatives to a contrastive approach but rather natural companions.

\section{COMPARISONS}

It may help to situate the contrastive treatment of causation in the law that I am defending by comparing it with three important recent views of causation in the law. The first two views I consider-from Moore and from Stapleton-are noncontrastive and seemingly diametrically opposed. ${ }^{58}$ I argue that contrastivity makes the best sense of both views, while helping reconcile their most plausible aspects. The third view I consider-from Broadbent (extending ideas from Peter Lipton, and also from Schaffer) is a contrastive approach to causation in the law. ${ }^{59} \mathrm{I}$ argue that my version of the contrastive view improves on the particulars of Broadbent's account.

58. MoORE, supra note 2; and Stapleton, supra note 5.

59. Broadbent, supra note 5; Lipton, Causation Outside the Law, supra note 29; Schaffer, Contrastive Causation, supra note 6. 
A. Reconciling Moore and Stapleton

\section{Moore on the Metaphysical Basis for Legal Liability}

Starting with Moore's view of causation in the law, his central claim is that "causation as a prerequisite to legal liability is intimately related to causation as a natural relation lying at the heart of scientific explanation." ${ }^{" 60}$ His guiding idea is that the concept of causation invoked in the law is not some specially defined legal notion (in contrast to a notion such as malice, for which the law explicitly adopts a special definition). Rather when the law says "causation," it means causation-the very same relation invoked by scientific explanation and commonsense thought. Moore's project is then to triangulate between legal, scientific, and metaphysical considerations in order to pinpoint this unified notion of causation.

Moore's project brings him to several conclusions about causation. Perhaps his primary conclusion is that we need a singularist conception of causation. ${ }^{61}$ A singularist conception denies that token causal relations are grounded in laws of nature, counterfactuals, or any other general features of the world. The contrast is with generalism, as seen in nomic sufficiency and counterfactual dependency accounts. (Moore remains neutral as between versions of singularism that reduce token causal relations to token physical processes such as energy flows and those that treat token causal relations as metaphysically primitive.)

But a second major conclusion Moore draws, which he calls "One of the great strengths of most singularisms, ${ }^{62}$ and which he defends repeatedly, ${ }^{63}$ is that absences cannot be causal. Moore is thereby driven to heroic lengths to make sense of legal liability. For Moore is of course aware that there is legal liability—as well as moral responsibility—arising with absences, for instance in certain cases of negligence. Moore's primary idea is to hold a disjunctive account of the grounds for legal liability and moral responsibility, according to which causation provides the primary ground for liability and responsibility, ${ }^{64}$ but mere counterfactual dependence without causation (which is what Moore thinks is found with absences) provides a secondary ground for liability and responsibility of a diminished sort.

Moore's denial of absence causation combined with his disjunctive account of the grounds of liability generates a host of further problems. ${ }^{65}$ One problem is the beheading problem. Since the route from decapitation to death involves the absence of blood flow to the brain (Sec. I.B), on Moore's view it follows that beheading someone cannot cause their death. Further absurdities follow. Moore must thereby deny that the act of beheading

60. MoOre, supra note 2 , at vii.

61. Id., ch. 20 .

62. Id. at 508 .

63. Id., chs. 3, 5, 6, 13, and especially 18 .

64. Id., ch. 18.

65. Jonathan Schaffer, Disconnection and Responsibility, LEGAL THEORY (forthcoming). 
someone can kill them or can satisfy the legal definition of homicide. Moreover, Moore can only ascribe to the beheader the diminished level of responsibility due to mere counterfactual dependence. Indeed, in cases where a preempted backup beheader is afoot, Moore will find neither causation nor counterfactual dependence and so must grant the preempting beheader complete legal and moral impunity. ${ }^{66}$

A second problem Moore faces is the problem of correlates. By his lights counterfactual dependence can hold between correlates of a common cause (related like thunder and lightning) ${ }^{67}$ Granting arguendo that Moore is right about the extent of counterfactual dependence, he must be wrong about its moral implications, for evidently there is no moral responsibility attaching to an act in virtue of its being the mere correlate of a crime.

The contrastive approach-by allowing for absence causation (Sec. I.B)avoids the implausible aspects of Moore's approach. Contrast allows negligent omissions to count as causal, so a disjunctive account of legal liability is not needed. This avoids the problem of correlates. Test rules that decapitating someone rather than leaving them alone can cause them to die rather than survive. This resolves the beheading problem from the outset. ${ }^{68}$

But what I would emphasize is that the contrastive approach preserves Moore's plausible unifying idea that the concept of causation at work in the law is the same concept as found in scientific explanation and commonsense thought. It thus preserves Moore's fruitful thought that scientific and metaphysical considerations can shed light on the law. In that sense it preserves the most plausible and central aspect of Moore's view.

\section{Stapleton on the Need to Specify an Inquiry}

Turning to Stapleton on causation in the law, her primary claim is that causal judgments in the law are used "to express diverse information about the world," so that we need to "specify an inquiry" to clarify the causal judgment. ${ }^{69}$ As a result, she rejects the idea-which Moore and I both endorse-that a "freestanding metaphysical account" can shed light:

Because the same causal language has been used to convey different types of information, it is futile for philosophers to search for a coherent freestanding metaphysical account of "causation" unless a choice of underlying interrogation (blame, explanation, physical role, any sort of involvement etc) is specified at the outset. ${ }^{70}$

66. See Moore, supra note 2, especially 461-463, for an initial reply to the beheading problem; and Schaffer, Disconnection, supra note 65 , especially $\S 2.4$, for a rejoinder.

67. MOORE, supra note 2, at 400-403.

68. This is not to say that the law marks no distinction between actions and omissions, for instance in the characterization of duties. It is only to say that both may play a role in the causal element of liability.

69. Stapleton, supra note 5 , at 433.

70. Id. at 439 . 
There are at least two respects in which Stapleton maintains that an inquiry needs to be specified. The first respect (already explicit in the previous quote) concerns the purpose behind the causal judgment. She illustrates this with an overdetermination case in which two hunters simultaneously and independently fire fatal shots at a hiker (after a hunting official has negligently failed to warn either hunter of the hiker's presence):

A legal interrogator might ask: do we blame Hunter No. 1 even thought the death would have happened anyway (yes). A citizen might ask: did the victim's presence explain his death (no). A scientist might ask: did gravity play a role in the death (yes). ${ }^{71}$

She ultimately argues that for the law to serve its various purposes, it needs the widest conception of causal involvement which takes in all of these factors as causal:

[Involvement] provides the width of coverage that is needed to accommodate smoothly all the many diverse enquiries the Law makes. For example, in the hunters case one project of the Law might be to consider all possible regulatory strategies for preventing such deaths. Such a project requires the Law to address all involved factors-even those that some might describe as "mere conditions," such as the walker's presence. This is because the most efficient strategy may be, for example, to ban mountain walking during the hunting season. ${ }^{72}$

But in specifying causal involvement as the conception of causation relevant to the law, Stapleton ought then to be open to the prospect of a freestanding metaphysical account of causal involvement. Or at least, her worry that the metaphysician has failed to specify whether the issue be blame, explanation, or involvement (etc.) would dissipate if the metaphysician were to specify at the outset that she was looking for an account of involvement. So in that sense it seems to me that Stapleton has by her own lights vindicated metaphysical inquiry into causation, when explicitly targeted at the widest notion of involvement. I would add only that, though "involvement" is Stapleton's term, metaphysicians have explicitly looked to target the widest notion in the area. For instance, Lewis - drawing on J.S. Millsays: "I am concerned with the prior question of what it is to be one of the causes (unselectively speaking). ${ }^{, 73}$ He adds:

We sometimes single out one among all the causes of some event and call it "the" cause, as if there were no others. Or we single out a few as the "causes," calling the rest mere "causal factors" or "causal conditions." ... We may select the abnormal or extraordinary causes, or those under human control, or those

73. Lewis, supra note 10, at 162; J.S. Mill, A System OF Logic (Macmillan 1950) (1843). 
we deem good or bad, or just those we want to talk about. I have nothing to say about these principles of invidious discrimination. ${ }^{74}$

So while I agree with Stapleton that a freestanding metaphysical account requires clarity with respect to what we are accounting for, I think that Stapleton herself has shown how this level of clarity can be achieved and that the philosophers have in fact already achieved this level of clarity (just with different terminology). ${ }^{75}$

Indeed, given that Stapleton recognizes a clear and important conception of causal involvement, it seems that the metaphysical question of what this relation is ought to be an urgent one for her. So in that sense Contrast can be understood as addressing a lacuna in her account concerning the metaphysics of causal involvement. (Contrast can be understood as a thesis about the number and roles of the relata of Stapleton's involvement relation.)

A second respect in which Stapleton maintains that an inquiry needs to be specified concerns the kind of conceptual filtering devices in place. She notes:

[I]n contrast to metaphysics, the conceptual framework and methodology of the Law provide filtering devices: that specify a small finite number of factors whose possible involvement in the existence of a particular phenomenon is subject to investigation; that pinpoint which particular phenomenon in the actual world is being examined; that specify relevant hypothetical comparator worlds; and that, within both the actual world and relevant hypothetical worlds, individuate the factor and the phenomenon of interest given the purposes of the legal enquiry. ${ }^{76}$

Contrast-and in particular Causal Contrast in the Law-should be understood as providing an implementation of Stapleton's insight. In particular, where she notes that the law specifies "relevant hypothetical comparator worlds," I am trying to explain exactly how the law achieves such a specification. The guiding idea is that causal judgment in the law makes implicit reference to lawful conduct as the causal contrast, which is how the hypothetical comparator worlds are specified. ${ }^{77}$

74. LEWIS, supra note 10 , at 162.

75. Stapleton criticizes my own discussion of contrastive causation (Schaffer, Contrastive Causation, supra note 6) as being "the same doomed project of many other philosophers: a search for 'a broad and nondiscriminatory concept' of causation," adding, "it is only once we have chosen which is the underlying interrogation in our dialogue that we can infuse our causal language with unambiguous meaning." Stapleton, supra note 5, at $439 \mathrm{n}$. 15 . But if what infuses our causal language with unambiguous meaning is the choice of something like causal involvement as the underlying interrogation, then the philosopher's project can go forward on that understanding. I would add that in my view the philosophers have already been working with that very understanding.

76. Stapleton, supra note 5, at 448.

77. The idea that the background inquiry serves to select the contrasts is an idea that traces back at least to MACKIE:

[C] ausal statements are commonly made in some context, against a background which includes the assumption of some causal field. A causal statement will be the answer to a causal question, and the question "What caused this explosion?" can be expanded into "What made the difference between those times, or those cases, within a certain range, 
In short, Contrast provides a freestanding metaphysical account of causal involvement. It thus fits with Stapleton's thought that a kind of inquiry needs to be specified, while speaking to the ensuing metaphysical question of the nature of the most general of these various specifiable relations (involvement). And Causal Contrast in the Law plus Effectual Contrast in the Law preserve Stapleton's insight that causal judgment in the law involves various conceptual filters. Indeed, they help illuminate exactly what some of these filters are and how they work.

Bringing together the discussions of Moore and Stapleton, I think Contrast not only preserves the most central and plausible insights of both theorists but may even point to a synthesis of their primary ideas. Metaphysically speaking, I am suggesting that there is a four-place relation of contrastive causation (in Stapleton's terms, contrastive causal involvement) at work in the law, scientific explanation, and commonsense thought. In so doing, I side with Moore in offering a freestanding metaphysical account, although, as argued above, Stapleton should not object to this project once it is specified that the account targets involvement. But I side with Stapleton in thinking that the application of this notion of causation is going to involve certain conceptual filters specific to the legal domain-namely, Causal Contrast in the Law and Effectual Contrast in the Law-and in thinking that Moore's metaphysics is inadequate for ruling out absence causation.

\section{B. Broadbent's Contrastive Approach}

Broadbent-building on ideas from Lipton and myself-develops a contrastive view of causation in the law, albeit one differing from mine in several particulars. ${ }^{78}$ I should note at the outset that Broadbent and I are mainly allies. We are both contrastivists of a sort. We can both claim to reconcile Moore's insight that metaphysical issues of causation are relevant to the law with Stapleton's insight that the law invokes its own special conceptual filters. But our views differ in the details, and a comparison may thus shed light on the work done (or left undone) by the various aspects of each of our accounts.

Broadbent summarizes his main view as follows:

Broadbent on Causation in Law: For a defendant's breach of duty to satisfy the causal element of liability with respect to a given harm to the claimant,

in which no such explosion occurred, and this case in which an explosion did occur?" Both causes and effects are seen as differences within a field.

MACKIE, supra note 54, at 34-35.

78. Broadbent, supra note 5; Lipton, Causation Outside the Law, supra note 29; Schaffer, Contrastive Causation, supra note 6. 
the breach must be a difference between the instant case and the legally appropriate foil in which the claimant did not suffer that harm. ${ }^{79}$

In other words, we are to ask the contrastive question "why did that harm $(e)$ occur, rather than a legally appropriate outcome without that harm $\left(e^{*}\right)$ ?" The idea is to see if the defendant's breach of duty made the difference between $e$ and $e^{*}$. The question then becomes whether $c$ would still have occurred in the hypothetical scenario that eventuates in $e^{*}$. To this Broadbent adds the following restriction on the legally appropriate contrast scenario $e^{*}$ :

Broadbent on Foils in Law: A foil is legally appropriate for proving that defendant's breach was a cause of damage only if the foil involves the mere meeting of the defendant's duty of care, not the meeting of the duty in some particular way beyond what the duty itself requires. ${ }^{80}$

There are at least three main differences between Broadbent's account and my own. A first difference concerns our targets. Broadbent aims to characterize the causal relation-or at least, he aims to articulate a necessary condition for satisfying the causal element of liability in terms that presuppose a form of contrastivity. I leave the notion of causal relatedness as intuitive and instead aim to characterize the number and roles of the causal relata. But this difference is more one of emphasis than of substancecertainly a contrastive account might aim at either or both targets.

A second difference concerns our use of the counterfactual notion of difference-making. Broadbent, following Lipton, starts from the effectual contrast $e^{*}$ and asks us to backtrack to see if $c$ is present earlier. I start from the causal contrast $c^{*}$ and, following Lewis, run the counterfactual scenario forward to see if $e^{*}$ is present later. This might seem like a minor difference about the evaluation of counterfactuals, made even more minimal by the fact that I use counterfactuals only in Test, which is not an official part of Contrast but just a useful heuristic for working with Contrast.

But actually there is a substantive difference that has legal consequences in cases such as Bolitho (Sec. II.B.2) ${ }^{81}$ In my discussion of Bolitho, I look at the hypothetical scenario in which the doctor attends to the child $\left(c^{*}\right)$. Running this scenario forward-given the evidence that the doctor would have chosen not to intubate-I find the child still dead at the end. The plaintiff does not meet with a better outcome. And in this way I get to agree with the law's judgment that the causal element of liability is lacking between the doctor's negligently failing to attend to the child and the child's death.

But Broadbent looks first to the alternative outcome in which the child survives. Rolling that scenario backward-given the evidence that

79. Broadbent, supra note 5 , at 187.

80. Id. at 189 .

81. I owe this point to Broadbent himself. 
intubation was required to save the life of the child-he finds the doctor in attendance at the start. And so he should find that the doctor's negligent failure to attend to the child is a difference-maker between $e$ and $e^{*}$ and so he should mistakenly find the causal element of liability to be present in Bolitho. So I conclude that there is an important difference, which shows up in Bolitho, between running a scenario forward from lawful conduct to see how it ends and rolling a scenario backward from the alternative outcome to see how it began. The Broadbent-Lipton backtracking notion of difference-making goes in the wrong direction for the law.

A third difference concerns the consideration of a causal contrast $c^{*}$. I say that the law must consider the specific hypothetical scenario $c^{*}$ in which the defendant acts lawfully, not the general hypothetical that the defendant's actual breach of duty does not occur, since the latter can involve irrelevant scenarios in which some other (perhaps worse) breach of duty occurs instead. Broadbent, following Lipton, specifies only an effectual contrast. He has no causal contrast. Where I treat the causal relation as four-place- $c$ rather than $c^{*}$ causes $e$ rather than $e^{*}$-Lipton and Broadbent treat it as three-place- $c$ causes $e$ rather than $e^{*} .{ }^{82}$

Broadbent's notion of a legally appropriate foil (as seen in Broadbent on Foils in Law) enters at this point to do the work that the causal contrast does in my account. What Broadbent essentially does is to take all the various scenarios in which the plaintiff does not suffer that harm, backtrack them all, and discard those that do not count as having legally appropriate beginnings. Given that what is legally appropriate is lawful conduct (Sec. II.A), Broadbent is essentially requiring that for the causal element of liability to hold, there be a scenario in which the plaintiff does not suffer that harm, which backtracks back to lawful conduct at the start. ${ }^{83}$ So understood, Broadbent and I are both interested only in comparisons between the actual scenario and the scenario in which the defendant acts lawfully. I achieve this comparison directly, via the alternative scenario $c^{*}$; Broadbent achieves this comparison indirectly, via a filter on the alternative outcomes $e^{*}$. I think my approach is more explicit, but that is a fairly minor difference.

82. I think the three-place view is independently objectionable-for reasons largely independent of the law-because it fails to allow causal chains. To form a causal chain we need the effect-structure at the first link to take the place of the cause-structure at the second link, and so we need to assign the same structure to the cause and the effect sides of the causal relation. Both the orthodox " $c$ causes $e$ " form and my contrastive " $c$ rather than $c^{*}$ causes $e$ rather than $e^{*}$ " form assign the same structure to both sides of the causal relation, and so can chain. But the Lipton-Broadbent " $c$ causes $e$ rather than $e^{*}$ " form does not assign the same structure to both sides of the causal relation, and so cannot chain.

83. Thus Broadbent, supra note 5 , at 190, introduces his filter of a legally appropriate foil in the context of developing my earlier claims about causation in the law to specify further how $c^{*}$ gets fixed in cases like NV Koninklijke Rotterdamsche Lloyd $v$. Western Steamship Co Ltd (The Empire Jamaica), [1955] 1 All E.R. 452. He also uses this filter to resolve his own hypothetical "Richard and Jane case" by specifying the alternative course(s) of conduct that the law considers salient for Richard and for Jane, in order to assess whether each of their actual breaches of duty causes a given harm. Id. at 190 . 
That said, I think that the way Broadbent runs the comparison with lawful conduct is inadequate, as may be seen in cases where the law allows multiple courses of conduct, such as Haft (Sec. II.A.2). I say that in cases where the law allows multiple courses of conduct, the defendant calls the shots and gets to specify the course of lawful conduct at issue (Sec. II.A.2). So in Haft, the defendant gets to specify the posting of a warning sign as the lawful conduct at issue. She can thereby refute any causal link between negligence and damage by arguing that posting a warning sign would not have made a difference. In this way I get to agree with the judgment of the law.

But Broadbent looks first to the alternative outcome in which the father and son survive. Rolling that scenario backward-assuming that only the presence of a lifeguard would have led to the survival outcome-Broadbent will find that the defendant has earlier met the duty of care by hiring a lifeguard. And so it seems as if Broadbent should mistakenly find the causal element of liability to be present in Haft, much in the same way as he runs into trouble in Bolitho.

With Haft, though, it might seem that Broadbent's conception of a legally appropriate foil can rescue him-indeed it might seem designed for cases of this ilk. In particular, he can say that the $e^{*}$ scenario that backtracks to the hiring of a lifeguard is not legally appropriate, on ground that it does not involve the mere meeting of the defendant's duty of care but rather involves the meeting of the duty in some particular way beyond what the duty itself requires.

But if Broadbent takes this line, then he must say that there is no possible way that the causal element of liability could have been established in Haft, whatever the evidence. For the owners of the hotel had two ways to meet their duty of care. They could have posted a warning sign or hired a lifeguard. If either way counts as a meeting of duty in some particular way beyond what the duty itself requires, then the defendants can only possibly have met their duty in some particular way. They will have no possible way to have merely met their duty. ${ }^{84}$ This means that Broadbent cannot allow for any legally appropriate foil, and so his account rules out legal causation a priori. In general, this would mean that breaching a duty with a disjunctive requirement could not possibly cause any damages, whatever the evidence. This would be a disaster.

Consider a hypothetical variant on Haft in which the plaintiff could show that posting the sign would have been effective. For instance, imagine evidence coming to light showing that the father had a history of heeding similar warning signs. I take it that causation would have been established in this hypothetical variant. But Broadbent's account-with his notion of

84. Indeed there is a sense in which any scenario that involves the defendant's meeting her duty of care must involve her meeting her duty of care in some particular way. Just as it is metaphysically impossible to have a generic color that is not some specific shade, so it is metaphysically impossible for a scenario to feature a meeting of a duty generically without featuring a meeting of that duty in some particular way. 
a legally appropriate foil applied as imagined-would rule otherwise. So, putting the dilemma together, either (i) Broadbent must allow that the negligence of the hotel owners did cause the death of the father and son in Haft, against the judgment of the law; or (ii) Broadbent can rule out causation by denying that hiring a lifeguard is a legally appropriate foil, but then he must say that it is a priori impossible for there to be causation in any case like Haft. Broadbent's way of drawing the comparison with lawful conduct is inadequate. ${ }^{85}$

I should reiterate that Broadbent and I are mainly allies and that we have quite similar contrastive perspectives on causation in the law. But we offer subtly different characterizations of the way in which causation in the law is contrastive, and the differences matter.

\section{REFERENCES}

Armstrong, David. (1999) “The Open Door: Counterfactual versus Singularist Theories of Causation." In Howard Sankey, ed., Causation and Laws of Nature, 175-185 (Kluwer Academic).

Broadbent, Alex. (2009) "Fact and Law in the Causal Inquiry." Legal Theory 15: 173-191.

Craver, Carl. (2007) Explaining the Mind (Oxford University Press).

Fumerton, Richard, and Ken Kress. (2001) "Causation and the Law: Preemption, Lawful Sufficiency, and Causal Sufficiency." Law and Contemporary Problems 64: 83-105.

Goodwin, W.M. (2008) "Structural Formulas and Explanation in Organic Chemistry." Foundations of Chemistry 10: 117-127.

Hart, H.L.A., and Tony Honoré. (1985) Causation in the Law, 2nd ed. (Clarendon Press).

Hitchcock, Christopher Read. (1993) “A Generalized Probabilistic Theory of Causal Relevance." Synthese 97: 335-364.

- (1996) "The Role of Contrast in Causal and Explanatory Claims." Synthese 107: 395-419.

Honoré, Tony. (2010) “Causation in the Law." In Stanford Encyclopedia of Philosophy, available at http:/ / plato.stanford.edu/entries/causation-law/.

Hume, David. (2007) (1740). "Abstract of A Treatise of Human Nature." In Peter Millican, ed., An Enquiry Concerning Human Understanding, 133-145 (Oxford University Press).

Lewis, David. (1986) “Causation.” In Philosophical Papers, vol. 2, 159-213 (Oxford University Press).

Lipton, Peter. (1990) “Contrastive Explanation.” In Dudley Knowles, ed., Explanation and Its Limits, 246-266 (Cambridge University Press).

85. I do not mean to suggest that Broadbent cannot possibly handle Haft. Indeed, my suggestion for him would be to revise his account of a legally appropriate foil to take up the ideas found in Lawful Conduct (Sec. II.A.2). So instead of saying that the legally appropriate foil is one that involves the mere meeting of the defendant's duty of care, he might say that it is one that involves minimal compliance with the duty alleged to have been breached by the plaintiff, in a form selected by the defendant. He could then take up my treatment of Haft. 
. (1992) "Causation Outside the Law." In Hyman Gross and Ross Harrison, eds., Jurisprudence: Cambridge Essays, 127-148 (Oxford University Press).

Mackie, J.L. (1974) The Cement of the Universe (Clarendon Press).

Maslen, Cei. (2004) "Causes, Contrasts, and the Nontransitivity of Causation." In John Collins, Ned Hall, and L.A. Paul, eds., Causation and Counterfactuals, 341-357 (MIT Press).

McGrath, Sarah. (2005) "Causation by Omission: A Dilemma." Philosophical Studies 123: $125-148$.

Mellor, D.H. (1995) The Facts of Causation (Routledge).

Mill, J.S. (1950) (1843) A System of Logic (Macmillan).

Moore, Michael. (2009) Causation and Responsibility (Oxford University Press).

Northcott, Robert. (2008) "Causation and Contrast Classes." Philosophical Studies 139: 111-123.

Paul, L.A. (2000) “Aspect Causation.” Journal of Philosophy 97: 235-256.

Pearl, Judea. (2000) Causality: Models, Reasoning, and Inference (Cambridge University Press).

Rooth, Mats. (1992). “A Theory of Focus Interpretation.” Natural Language Semantics 1: 75-116.

Schaffer, Jonathan. (2000) "Causation by Disconnection." Philosophy of Science 67: 285-300.

- (2004) "Causes Need Not Be Physically Connected to Their Effects: The Case for Negative Causation.” In Christopher Read Hitchcock, ed., Contemporary Debates in Philosophy of Science, 197-216 (Basil Blackwell). . (2005) "Contrastive Causation." Philosophical Review 114: 327-358.

. (2007) "The Metaphysics of Causation." Stanford Encyclopedia of Philosophy, available at http://plato.stanford.edu/entries/causation-metaphysics.

. (Forthcoming a) "Causal Contextualisms: Contrast, Default, and Model." In Martijn Blaauw, ed., Contrastivism in Philosophy (Routledge).

_. (Forthcoming b) "Disconnection and Responsibility." Legal Theory.

Spirtes, Peter, Clark Glymour, and Richard Scheines. (1993) Causation Prediction and Search (Springer-Verlag).

Stapleton, Jane. (2008) "Choosing What We Mean by 'Causation' in the Law." Missouri Law Review 73: 433-480.

Thomson, Judith Jarvis. (2008) “Some Reflections on Hart and Honoré.” In Matthew H. Kramer, Claire Grant, Ben Colburn, and Anthony Hatzistavrou, eds., Causation in the Law. The Legacy of H.L.A. Hart: Legal, Political and Moral Philosophy, 143-164 (Oxford University Press).

Van Fraassen, Bas. (1980) The Scientific Image (Oxford University Press).

Woodward, James. (2003) Making Things Happen: A Theory of Causal Explanation (Oxford University Press).

Wright, Richard. (1985) "Causation in Tort Law." California Law Review 73: 17371828.

. (2001) "Once More into the Bramble Bush: Duty, Causal Contribution, and the Extent of Legal Responsibility.” Vanderbilt Law Review 54: 1071-1132. 